\title{
Limiting partial molar volumes of Potassium aluminium sulphate in dimethyl sulphoxide + water at different temperatures
}

\author{
R. S. Khairnar ${ }^{1}$, K.R. Labhade ${ }^{2}$ \\ Department of Chemistry, S. V. K. T. Arts, Science and Commerce College, Deolali-Camp (Nashik) Pin-422401 \\ Maharashtra state, India.
}

\begin{abstract}
Densities of potassium aluminium sulphate have been measured in dimethyl sulphoxide (DMSO) + water, containing 0,5,10,15, and 20 mass percent of DMSO, at different concentration and at 298.15, 303.15, 308.15 and $313.15 \mathrm{~K}$. From the densities, apparent molar volumes have been derived. The apparent molar volume data have been analyzed using Masson equation. The limiting molar volumes, ${ }_{v} \phi^{0}$, and $S_{v}{ }^{*}$ slop are interpreted in terms of solute-solvent and solute-solute interactions respectively. The ${ }^{0} \phi^{0}$ values vary with temperature as power series of temperature. Finally, the structure making/ breaking capacities of salts have been inferred from the Hepler's criterion.
\end{abstract}

\section{Introduction}

Thermodynamic investigation play important role in understanding type and extend of the pattern of molecular associations that exist in liquid mixtures and their sensitivities to variation in composition, temperature, pressure and chemical nature[1]. The partial molar of salt is an important thermodynamic property.

Ion-solvation [2-4] and electrochemical studies [5-6] in aqueous-DMSO are popular. So the thermodynamics of ion-solvent interaction in this system is of considerable importance.

As partial molar volumes of a solute reflects the cumulative effects of ion-ion and ion-solvent interactions [7-8], it would be of interest to study partial molar volumes of potassium aluminium sulphate a in dimethyl sulphoxide(DMSO) + water system.

\section{Materials and methods}

Water was distilled in a quick-fit apparatus over alkaline $\mathrm{KMnO}_{4}$, followed by further distillation over $\mathrm{H}_{2} \mathrm{SO}_{4}$. The electrical conductance of distilled water varied between $7 \times 10^{-7}$ to $9 \times 10^{-9} \mathrm{ohm}^{-1} \mathrm{~cm}^{-1}$. A. R. grade DMSO (99.5 pure, s. d. fine-chem.) was carefully dried by refluxing for 24 hours over $\mathrm{CaO}$. It was left in contact with drying agent for about 10 days with occasional shaking and then fractionally distilled under reduced pressure. The middle fraction with boiling point approximately $68^{\circ} \mathrm{c}$, at $6-7 \mathrm{~mm}$ pressure, was collected and used in all physical measurements. The purity of DMSO was ascertained by comparing densities at different temperatures with the corresponding literature values [9] which match well. Conductivity water and purified DMSO mixed together to give 5, 10, 15, and 20 mass \% DMSO mixtures, which served as solvents.

Salts were supplied by s d fine-chem. and Ranbaxy laboratory (purity $>99.5 \%$ ). All salts were dried over $\mathrm{P}_{2} \mathrm{O}_{5}$ to constant mass before use. Accurately known masses of salts (accuracy $\pm 0.01 \mathrm{mg}$ ) were dissolved in a particular solvent to give concentration of $0.1 \mathrm{M}$. This served as the stock solution. Further concentrations were obtained by using mass dilution technique. Salts concentrations varied from 0.008 to $0.1 \mathrm{M}$. The solutions were stored in dark colored amber bottles which were kept in a dry box.

Densities were measured by using a $16 \mathrm{~cm}^{3}$ double-arm pycnometer as described earlier [10]. The pycnometer was calibrated using conductivity water with $0.99705 \mathrm{~g} \mathrm{~cm}^{3}$ as its density at $298.15 \mathrm{~K}$ [11]. The pycnometer filled with air bubble-free experimental liquids was kept in a transparent-walled water bath (maintained constant to $\pm 0.01 \mathrm{~K}$ ) for 10 to 15 minutes minimum to attain thermal equilibrium. The position of the liquid levels in the two arms was recorded with the help of a traveling microscope which could be read to $\pm 0.01 \mathrm{~mm}$. The estimated accuracy of density measurement was $\pm 0.00002 \mathrm{~g} \mathrm{~cm}^{-3}$.

\section{Results and discussion}

The densities (d) and apparent molar volumes of potassium aluminium sulphate at 298.15, 303.15, 308.15 and $313.15 \mathrm{~K}$ are summarized in Table 1 . expression,

The apparent molar volumes ${ }_{v} \phi$ were calculated from the accurate density data using the following

$$
{ }_{\mathrm{v}} \mathrm{\phi}=1000\left(\mathrm{~d}_{0}-\mathrm{d}\right) / \mathrm{cd}_{0}+\mathrm{M}_{2} / \mathrm{d}_{0}
$$

Where $\mathrm{c}$ is the molar concentration of solute, $\mathrm{d}$ and $\mathrm{d}_{\mathrm{o}}$ are the densities of solution and solvent respectively, and $\mathrm{M}_{2}$ is the formula weight of the solute. 
The limiting apparent molar volume, ${ }_{v} \phi^{0}$, were calculated using the least squares fit to the plots of experimental values of ${ }_{v} \phi$ against the square root of molar concentration $c$ by the Masson empirical equation[12];

$$
{ }_{v} \phi={ }_{v} \phi^{0}+S_{v}{ }^{*} c^{1 / 2}
$$

where $S_{v}{ }_{v}^{*}$ is a constant dependent on charge and salt type and can be related to ion-ion interactions and ${ }_{v} \phi^{0}$ is the partial molar volume at infinite dilution.

Table 1

Concentration(c), Density (d) and apparent molar volumes, ${ }_{v} \phi$, values for potassium aluminium sulphate in DMSO + water at different temperatures 298.15K 303.15K 308.15K 313.15K

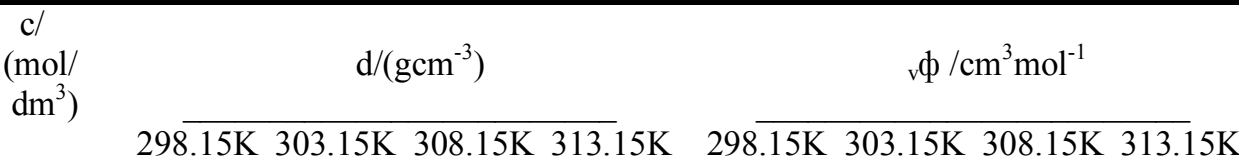

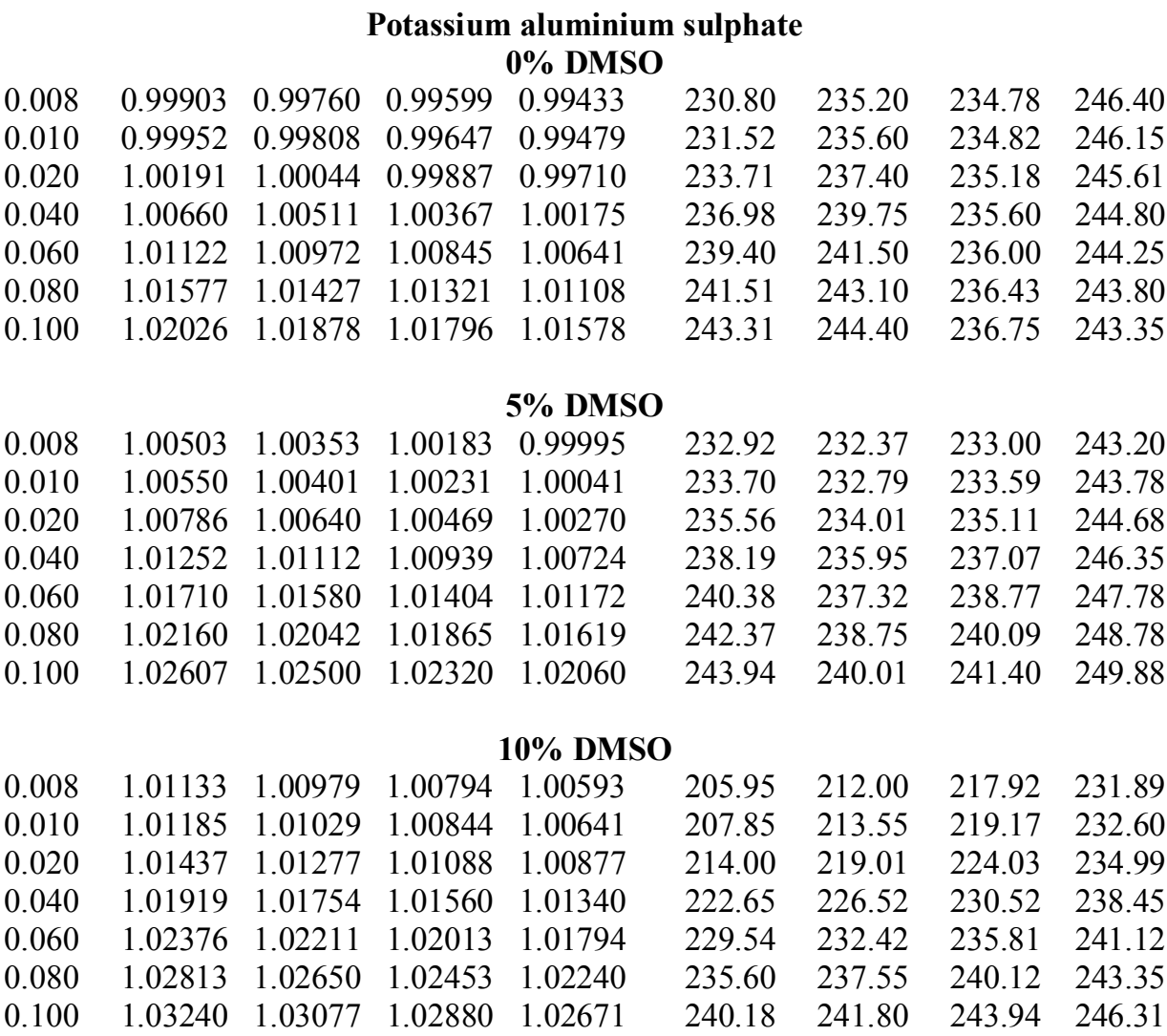

Table 1 continued.......

\begin{tabular}{|c|c|c|c|c|c|c|c|c|}
\hline \multirow{2}{*}{$\begin{array}{c}\mathrm{c} / \\
(\mathrm{mol} / \\
\left.\mathrm{dm}^{3}\right)\end{array}$} & \multicolumn{4}{|c|}{$\mathrm{d} /\left(\mathrm{gcm}^{-3}\right)$} & \multicolumn{4}{|c|}{$\mathrm{v} \phi / \mathrm{cm}^{3} \mathrm{~mol}^{-1}$} \\
\hline & $298 \overline{15 \mathrm{~K}}$ & $303.15 \mathrm{~K}$ & $308.15 \mathrm{~K}$ & $313.15 \mathrm{~K}$ & $298 . \overline{15 \mathrm{~K}}$ & $303.15 \mathrm{~K}$ & $308.15 \mathrm{~K}$ & 313.1 \\
\hline \multicolumn{9}{|c|}{ 15\% DMSO } \\
\hline 0.008 & 1.01806 & 1.01618 & 1.01425 & 1.01200 & 200.81 & 212.01 & 215.19 & 221 \\
\hline 0.010 & 1.01858 & 1.01668 & 1.01475 & 1.01249 & 203.00 & 213.38 & 216.58 & 222 \\
\hline 0.020 & 1.02105 & 1.01915 & 1.01720 & 1.01489 & 213.56 & 219.01 & 221.68 & 227. \\
\hline 0.040 & 1.02597 & 1.02388 & 1.02193 & 1.01955 & 219.03 & 226.62 & 228.28 & 0 \\
\hline
\end{tabular}




\begin{tabular}{lllllllll}
0.060 & 1.03032 & 1.02840 & 1.02648 & 1.02404 & 230.38 & 232.76 & 233.59 & 237.95 \\
0.080 & 1.03453 & 1.03277 & 1.03088 & 1.02840 & 237.69 & 237.62 & 238.01 & 241.96 \\
0.100 & 1.03857 & 1.03700 & 1.03515 & 1.03266 & 243.82 & 241.97 & 241.91 & 245.33 \\
\multicolumn{8}{c}{ 20\% DMSO } \\
0.008 & 1.02505 & 1.02301 & 1.02073 & 1.01838 & 201.63 & 205.79 & 217.04 & 223.44 \\
0.010 & 1.02556 & 1.02351 & 1.02121 & 1.01886 & 204.00 & 208.59 & 218.95 & 225.04 \\
0.020 & 1.02799 & 1.02593 & 1.02360 & 1.02120 & 214.84 & 218.45 & 225.41 & 230.60 \\
0.040 & 1.03250 & 1.03030 & 1.02812 & 1.02570 & 229.22 & 234.44 & 234.45 & 237.95 \\
0.060 & 1.03660 & 1.03450 & 1.03240 & 1.03000 & 240.54 & 242.64 & 241.53 & 243.72 \\
0.080 & 1.04040 & 1.03830 & 1.03951 & 1.03414 & 249.85 & 251.59 & 247.18 & 248.58 \\
0.100 & 1.04395 & 1.04186 & 1.04043 & 1.03812 & 257.95 & 259.40 & 252.39 & 253.05
\end{tabular}

The values of ${ }_{\mathrm{v}} \phi^{0}$ and $\mathrm{S}_{\mathrm{v}}{ }^{*}$ estimated by computerized least squares method, correlation coefficient greater than 0.999 , along with standard errors are included in Table 2.

Table 2, lists the estimated ${ }_{\mathrm{v}} \phi^{\mathrm{O}}$ and $\mathrm{Sv}^{*}$ values of each salt in different mass \% DMSO.

Table 2

Limiting partial molar volumes $\left({ }_{v} \phi^{0}\right)$ and experimental slopes $\left(S_{v}{ }_{v}{ }^{*}\right)$ of salts in DMSO+ water at different temperatures

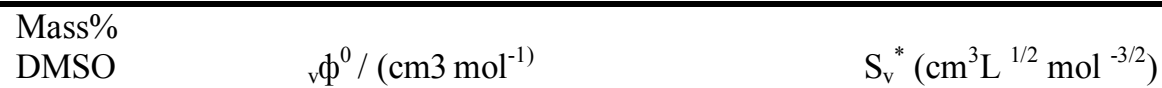

$298.15 \mathrm{~K} 303.15 \mathrm{~K} 308.15 \mathrm{~K} 313.15 \mathrm{~K} \quad 298.15 \mathrm{~K} 303.15 \mathrm{~K} 308.15 \mathrm{~K} 313.15 \mathrm{~K}$

\begin{tabular}{rrrrrrrrrr}
\multicolumn{8}{c}{ Potassium aluminium sulphate } \\
0 & 225.96 & 231.59 & 233.95 & 247.50 & 54.94 & 40.62 & 08.65 & -13.19 \\
& $(0.07)$ & $(0.07)$ & $(0.09)$ & $(0.08)$ & $(0.35)$ & $(0.35)$ & $(0.45)$ & $(0.37)$ \\
5 & 228.74 & 229.37 & 229.87 & 240.70 & 42.92 & 33.14 & 36.30 & 28.75 \\
& $(0.19)$ & $(0.18)$ & $(0.14)$ & $(0.19)$ & $(0.89)$ & $(0.85)$ & $(0.65)$ & $(0.89)$ \\
10 & 192.57 & 200.37 & 207.72 & 226.30 & 151.11 & 131.11 & 114.56 & 61.54 \\
& $(0.30)$ & $(0.14)$ & $(0.11)$ & $(0.51)$ & $(1.43)$ & $(0.67)$ & $(0.54)$ & $(2.38)$ \\
15 & 184.62 & 200.20 & 204.86 & 212.46 & 186.20 & 132.33 & 117.26 & 104.19 \\
& $(2.70)$ & $(0.14)$ & $(0.19)$ & $(0.33)$ & $(12.67)$ & $(0.66)$ & $(0.93)$ & $(1.55)$ \\
20 & 179.36 & 185.25 & 203.35 & 212.05 & 249.17 & 235.80 & 155.30 & 129.48 \\
& $(0.31)$ & $(1.52)$ & $(0.20)$ & $(0.22)$ & $(1.45)$ & $(7.15)$ & $(0.96)$ & $(1.05)$
\end{tabular}

Values in parenthesis are standard errors.

$\mathbf{S}_{\mathbf{v}}{ }^{*}$ values are goes on increasing as the mole fraction of DMSO in binary aqueous solution increases from these values, it may be inferred that solute-solute interactions are large and increases in DMSO content in water. The negative sign of $\mathrm{Sv}^{*}$ for potassium aluminium sulphate in 0 mass \% DMSO at $313.15 \mathrm{~K}$ reveals weaker solute-solute interactions. $\mathbf{S}_{\mathbf{v}}{ }^{*}$ decreases with rise in temperature in a solvent, which attributes to more violent thermal agitation at higher temperature resulting in diminishing force of solute-solute interaction (ionic dissociation) $[13,14]$.

To examine the solute-solvent interaction, the ${ }_{\mathrm{v}} \phi^{0}$ values can be used. The positive values of ${ }_{\mathrm{v}} \phi^{0}$ (Table 2$)$ in any solvent indicate that solvent molecules are loosely attached to solute which expands with increase of temperature, thus resulting in higher values of ${ }_{\mathrm{v}} \phi^{0}$ at higher temperature. At a particular temperature, ${ }_{\mathrm{v}} \phi^{0}$ decreases with increase in mass \% DMSO Potassium aluminium sulphate under investigation; suggest solutesolvent interaction decreases with the increase of DMSO content. Similar results are reported for sucrose and urea in aqueous DMSO [15].

The variation of ${ }_{\mathrm{V}} \Phi^{0}$ with temperature of the salts in solvents follows polynomial equation.

$$
{ }_{\mathrm{v}} \Phi^{0}=\mathrm{a}_{0}+\mathrm{a}_{1} \mathrm{~T}+\mathrm{a}_{2} \mathrm{~T}^{2}
$$

Over the temperature range under the investigation, the coefficients $a_{1}$ 's are presented in Table 3 . 
Table 3

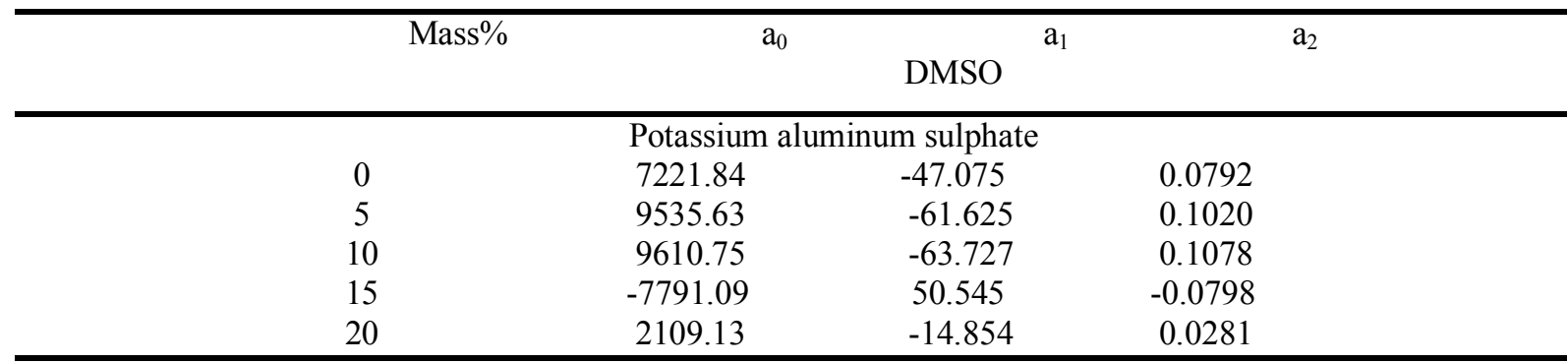

Since the increase in ${ }_{\mathrm{V}} \Phi^{0}$ with increase in temperature is attributed to increase in solvation, on raising the temperature some solvent molecules may be released from the loose solvation layer of the solute in solution. The salvation is more for potassium aluminum sulphate in all solvents. It is observed that the partial molar volume expansibility, ${ }_{\mathrm{E}} \Phi^{0}=\left[\partial_{\mathrm{V}} \Phi^{0} / \partial \mathrm{T}\right]$ increase with increase of temperature. These results can be ascribed to the presence of caging effect [16]. The positive value of ${ }_{\mathrm{E}} \phi^{0}$ for salts in different mass $\%$ DMSO indicates the behavior of salts just like the behavior of symmetrical tetraalkylammonium salts, unlike those of the common salts because for them the molar expansibility should decrease with the increasing temperature [1].

For determining long-range structure-making and structure-breaking capacities of solute in different solvent, following equation of Hepler was used [17]:

$$
[\partial \mathrm{Cp} / \partial \mathrm{p}]=-\left[\partial^{2}{ }_{\mathrm{v}} \Phi^{0} / \partial \mathrm{T}^{2}\right]_{\mathrm{p}}
$$

The values of term are summarized in Table 4 .

Table 4

The term - $\left[\partial^{2}{ }_{v} \Phi^{0} / \partial T^{2}\right]_{p}$ for salts in DMSO + water

Electrolyte $\quad 0 \%$ DMSO $\quad 5 \%$ DMSO $\quad 10 \%$ DMSO 15\%DMSO 20\%DMSO

\begin{tabular}{llllll}
\hline $\begin{array}{c}\text { Potassium aluminium } \\
\text { Sulphate }\end{array}$ & 0.1584 & 0.2040 & 0.2156 & -0.1596 & 0.0562 \\
\hline
\end{tabular}

According to Hepler, structure -making solutes should have positive value and structure-breaking solutes should have negative value of the term

$\left[\partial^{2}{ }_{v} \Phi^{0} / \partial \mathbf{T}^{2}\right]_{p}$

In the present study the above term is positive for potassium aluminium sulphate in $0,5,10$ and 20 mass \% DMSO indicating structure-making tendency of this salt in the present system.

\section{References}

[1]. F. J. Millero, chem.Rev. 1971, 71, 147

[2]. B. G. Cox, R. N. Natarajan and W. E. Waghorem J.Chem. Soc. Faraday Trans. 1.

[3]. S. Janardhanan and C. Kalidas, Bull.Chem.Soc.Jpn.53(1980) 2363.

[4]. A.J.Q.Parkaer, Rev. Chem.Soc., 16(1962) 163.

[5]. R. J. Jassinski, High Energy Batteries, Plenum, New York, (1967)

[6]. E.Buncil and H. Wilson, Adv.Phys.Org.Chem. 14, (1977)133.

[7]. P. S. Nikam and A. B. Sawat, J.Che.Eng. Data, 42(1997) 585

[8]. P. S. Nikam and A. B. Sawant, Bull Soc.Jpn, 71 (1998) 2055

[9]. J. A. Riddick, W. B. Bugar and T. K .Sakano, "Organic Sovents: Physical Properties and Physical Methods of Purification. Techniques of Chemistry", 4th ed. Wiley-Intercience. New York, 1986. Vol. 11

[10]. P. S. Nikam and A. B. Sawant, J.Molecular Liquids, 75 (1988)199.

[11]. K. N. Marsh, "Recommended Reference Materials for the Realization of Physicochemical Properties, "Blackwell Scientific Publication, Oxford, (1987)

[12]. D. O. Masson, Philos.Mag., 8(1929)218.

[13]. M. L. Parmar, B. Bhardwaj and S. C. Attri, J. Indian Chem. Soc., 75 (1998) 402.

[14]. P. S. Nikam and A. B .Sawant, R. S. Khairnar and J. S. Aher J.Molecular Liquids, 81 (1998) 253.

[15]. B. Das and D. K. Hazra, J. Chem. Eng. Data, 36(1991)463.

[16]. F. J. Millero, In "Water and Aqueous Solutions (Structure, Thermodynamics, and Transport Processes)," ed R. A. Horne, WileyInterscience, New York, Chap. 13(1972)

[17]. L. G. Hepler, Can. J. Chem., 47(1969) 4613. 